\title{
Social and emotional impact of faecal incontinence after surgery for anorectal abnormalities
}

\author{
L Ludman, L Spitz, E M Kiely
}

\begin{abstract}
A significant proportion of children with anorectal malformations have long term problems with faecal continence. The psychological consequences of this chronic disability was assessed in 160 children and adolescents.
\end{abstract}

The prevalence of clinically significant emotional problems among the sample overall, as assessed by a diagnostic psychiatric interview $(19 \%)$, parental assessment $(27 \%)$, and child self report depressive scale $(24 \%)$ was higher than expected relative to normative populations. With the exception of the young girls (6-11 years), the incontinent children and adolescents were not judged to be less well adjusted than those with good bowel control.

Treatment for anorectal malformations appears to be associated with an increased risk for behavioural and social problems, but this was not related to the level of continence. Parental factors and gender were significantly associated with outcome. These children and families would benefit from psychological evaluation and support especially during early childhood. (Arch Dis Child 1994; 71: 194-200)

Children with chronic disorders are at increased risk. for behavioural and social problems, psychiatric disturbance, ${ }^{12}$ and impaired emotional adjustment. ${ }^{3}$ Even mild chronic disorders have been shown to increase a child's psychological vulnerability, ${ }^{4}$ and an association between physical and psychological disorders has also been demonstrated. ${ }^{5}$ Other research has suggested that there are no marked differences between children in several disease categories and comparable controls. ${ }^{67}$ Although a high proportion of children born with anorectal abnormalities have long term problems with faecal incontinence, little is known about the psychosocial consequences. Ditesheim and Templeton assessed 'quality of life' in relation to the success or failure of attaining faecal continence, ${ }^{8}$ and Ginn-Pease $e t$ al reported on the psychological adjustment of children with imperforate anus or abdominal wall defects. ${ }^{9}$

The aim of this study was to assess the emotional and social adjustment of children with anorectal malformations in relation to the level of continence achieved, and to assess whether the prevalence of behavioural and emotional disturbance increases during adolescence.
This paper constitutes the first in a series of reports and focuses on the question of whether children with faecal incontinence fare less well emotionally than those who achieve continence. Further reports will address the issues of how the children cope with this chronic disability and whether parental, sibling, and peer responses have an impact on the child or adolescents' functioning.

\section{Patients and methods}

The case notes of all patients who had their primary definitive surgery for anorectal anomalies performed at Great Ormond Street Children's Hospital (GOS) between 1974 and 1987 were reviewed to ascertain which fulfilled the criteria for our study. Eligibility criteria excluded children who did not undergo primary definitive surgery at GOS, those who were known to be developmentally delayed, and those with multiple handicaps, of which the anorectal malformation was only one component. Children currently living outside England and Wales were also excluded.

Altogether 223 patients aged 6-17 years were contacted by letter explaining the purpose of the study and requesting their participation; the patients comprised those who were still attending the hospital for medical or surgical follow up and those who had been discharged. Written consent was received from 160 families ( $72 \%) ; 52$ families (23\%) could not be located, and only $11(5 \%)$ did not agree to participate.

The study sample comprised 90 boys and 70 girls (mean (SD) age 11.3 (3.4) years). Eighty one were aged between 6 and 11 years (designated as children) and 79 were aged between 12 and 17 (designated as adolescents).

Characteristics of the study sample are shown in table 1 .

\section{PROCEDURES AND INSTRUMENTS USED}

The study was designed to include a clinical examination followed by separate psychosocial interviews with the parents and the child or adolescent. In addition, both the parents and the children were asked to complete standardised questionnaires. Teachers were asked to complete standardised behavioural questionnaires.

After a clinical examination the surgeon completed a standard form designed for the study. In addition to surgical and medical details this included a classification of the 
Table 1 Characteristics of the sample $(n=160)$. Values are number (\%) unless otherwise stated

\begin{tabular}{lc}
\hline Mean (SD) age in years & $11 \cdot 3(3 \cdot 42)$ \\
Range & $6-17$ \\
Boys/girls & $90 / 70$ \\
Family size & $1-5$ \\
Range & $77(48)$ \\
First born & $16(10)$ \\
Only child & $6(4)$ \\
One of twin & \\
Family composition & $123(77)$ \\
Both biological parents & \\
Single parent & $18(11)$ \\
Mother & $2(1)$ \\
Father & $7(4)$ \\
Mother/father substitute & $8(5)$ \\
Other (grandparent, adopted, fostered, etc) & $22(14)$ \\
Ethnic minority background & \\
Social class & $81(54)$ \\
Non-manual & $52(34)$ \\
Manual & $12(8)$ \\
Unemployed/not working & $4(3)$ \\
Armed forces & $2(1)$ \\
Other & \\
Parental education & \\
No formal qualifications & $47(31)$ \\
Mother & $59(45)$ \\
Father & \\
CSE/'O' levels & $70(47)$ \\
Mother & $40(31)$ \\
Father & \\
'A'levels+ & $33(22)$ \\
Mother & $32(24)$ \\
Father & \\
\hline & \\
\hline &
\end{tabular}

anorectal anomaly as high, intermediate, or low according to the Wingspread classification system, ${ }^{10}$ and a clinical scoring measure (Kelly score) that grades levels of faecal continence. ${ }^{11}$ The total Kelly score ranges from 0 to 6 , with a score of 5 or 6 equated with continence and scores of four or less equated with incontinence.

The patients with low anomalies will have had immediate definite surgery in the newborn period, while those with high and intermediate anomalies will have had a staged procedure starting with a colostomy in the newborn period followed by a pull-through procedure and closure of the colostomy within the first year of life. Many required repeat admissions and/or further surgical procedures.

\section{Clinical data}

Altogether $59 \%$ of the subjects had high and intermediate anomalies and $41 \%$ low. As expected the number of boys with high and intermediate anomalies was greater than that for girls $(70: 24)$ whereas proportionately more girls had low anomalies (46:20). The relationship between the level of the anomaly and total Kelly scores for the study sample is shown in table 2. An analysis of variance (total Kelly score by sex) revealed a significant effect of gender ( F 3.94, df $1, \mathrm{p}<0.05)$, with the boys having a lower (worse) mean total Kelly score.

Table 2 Relationship between level of lesion and total Kelly score. Values are number (\%)

\begin{tabular}{llll}
\hline & \multicolumn{2}{l}{ Level of lesion } \\
\cline { 2 - 4 } & Low & Intermediate & High \\
\hline $\begin{array}{c}\text { Total Kelly score } \\
5 \text { or } 6\end{array}$ & $45(30)$ & $5(3)$ & $6(4)$ \\
$\leqslant 4$ & $17(12)$ & $12(8)$ & $63(43)$ \\
Total & $62(42)$ & $17(11)$ & $69(47)$
\end{tabular}

Total sample with total Kelly score 148 (no total Kelly score for eight cases; four cases had a permanent colostomy).
When, however, the level of the lesion was controlled for, the effect of gender was no longer significant (F 2.44, df $1, \mathrm{p}=0 \cdot 12)$.

\section{Measures of emotional and behavioural disturbance}

In order to measure a number of domains of child or adolescent functioning and to include measures from multiple perspectives, five measures of child or adolescent emotional and behavioural adjustment were used.

All assessments were carried out by a psychologist experienced in working with children and their families. The parent(s) were interviewed using a semistructured interview especially designed for the study. The interview included detailed questions about the child's continence level, and where appropriate methods of managing and coping with current and past bowel problems at home, at school, and socially. Questions also focused on the child's social life and personal relationships. The parents were also questioned about psychological and emotional symptoms in the child. Items from semistructured interviews, ${ }^{12} 13$ which have been shown to be reliable and valid instruments for assessing psychiatric disturbance were used to structure this part of the interview. Both parents were asked to complete the 30 item general health questionnaire, 14 to assess psychiatric morbidity, and the mothers were asked to complete a marital rating measure. ${ }^{15}$

The interview with the child or adolescent was similarly structured and included a standardised form of psychiatric interview modelled on the Child Assessment Schedule (CAS), ${ }^{16}$ and semistructured interviews. ${ }^{13} 17$ The CAS elicits information concerning symptoms reflective of Diagnostic and Statistical Manual of Mental Disorders, third edition, revised (DSM-III-R) categories of psychopathology in young people and has been shown to differentiate depressed, anxious, and conduct disordered young people. Data supportive of the reliability and validity of the CAS are well established. ${ }^{18-20}$ (When the child was interviewed their state of continence was known.)

While the patient was being interviewed the parents were asked to complete the newly revised Child Behaviour Checklist (CBCL). ${ }^{21}$ This is a parent rated measure of children's behaviour. The checklist yields a total behaviour problem score that is calculated by summing the scores $(0,1$, or 2$)$ from the 112 behaviour problem items. In addition two broad band subscales, referred to as internalising and externalising symptom scales, can be calculated. Internalising symptoms are those associated with neurotic or overcontrolled tendencies (social withdrawal, depression, anxiety) whereas externalising symptoms are those associated with conduct problems or undercontrolled behaviours (antisocial, aggressive, delinquent).

Separate scoring scales and normative data are provided for boys and girls as well as for children in the age ranges of 6-11 and 12-17 
Table 3 Psychiatric diagnosis. Values are number (\%)

\begin{tabular}{ll}
\hline $\begin{array}{l}\text { Psychological disorder } \\
\text { Dubious/mild }\end{array}$ & $16(10)$ \\
Definite/moderate & $30(19)$ \\
Total & $46 / 157(29)$ \\
Continent (total Kelly score 5 or 6) & \\
Dubious/mild & $4(7)$ \\
Definite/moderate & $8(15)$ \\
Total & $12 / 55(22)$ \\
Incontinent (total Kelly score 54$)$ & $10(11)$ \\
$\quad$ Dubious/mild & $21(23)$ \\
$\quad$ Definite/moderate & $31 / 90(34)$ \\
Total & $11(7)$ \\
Specific learning disorders & $9(6)$ \\
Borderline intellectual functioning & $20(13)$ \\
Academic problems $\dagger$ & $7(4)$ \\
\hline
\end{tabular}

No total Kelly scores for 12 cases; three children not interviewed.

$\star$ Two cases had physical handicaps severe enough to interfere with academic progress.

fOne child had a cerebrovascular accident after an accidental injury.

years. As recommended, $T$ scores of $\geqslant 60$ (corresponding to the 82 nd centile) were used as the cut off points for defining levels of clinical significance. ${ }^{21}$

While the parents were being interviewed the children were asked to complete a depression self rating scale (DSRS). ${ }^{22}$ This is an 18 item self report screening measure for affective disorders in childhood and adolescence. A cut off of 11 , recently recommended by Fundudis et al, was used. ${ }^{23}$ (The interviews with the child or adolescent were conducted blind to the results of the self report inventories.)

The children's teachers were asked to complete the Teacher's Report Form (TRF), ${ }^{24}$ which is modelled on the CBCL with additional items appropriate for teachers. (The teachers were told that the child had been admitted to GOS in early childhood, but were not necessarily aware of the nature of the child's medical problem.)

The study was approved by the ethical committee of GOS.

\section{Results}

Analyses were conducted to compare the psychological adjustment of the study group overall. The sample was also divided into two groups based on their level of continence as rated by the Kelly scoring method (total Kelly score 5 or 6 : continent $(n=56)$, total Kelly score $\leqslant 4$ : incontinent $(n=92)$. A total Kelly score was not available for eight children and four had permanent colostomies.

In order to compare our findings with existing normative data for the CBCL and TRF the sample was subdivided by sex and age (6-11 and 12-17 years). Three parents (2\%) did not complete the CBCL, eight teachers (5\%) did not return the TRF, and six adolescents were no longer at school $(4 \%)$; three children were not interviewed, and three did not complete the DSRS.

\section{(1) INTERVIEW DATA}

Forty six of the 157 children and adolescents interviewed (29\%) were judged as having some psychiatric disorder based on the diagnostic interview, ranging in severity from 'dubious or mild' in $16(10 \%)$ to definite or moderate in 30
(19\%). This prevalence of $19 \%$ is significantly higher than a one year prevalence rate of $10 \%$ in the general child population $(<0.001),{ }^{25}$ but is similar to that found in children with chronic disorders.

Eleven children and adolescents (7\%) met the criteria for the DSM-III-R diagnoses of specific developmental disorders (for example, developmental arithmetic and reading disorders), with a further nine $(6 \%)$ diagnosed as being of borderline intellectual functioning (that is, IQ range 71-84). In addition, three children (one boy and two girls) and four adolescent boys were having academic problems at school (4\%) (table 3).

Thirty two (20\%) were diagnosed as having neurotic (emotional) disorders, with a high proportion of these children and adolescents having anxiety disorders (20/32, 63\%). Five children $(3 \%)$ fulfilled the criteria for attention deficit hyperactivity disorder.

Analysis of the type and frequency of psychiatric diagnoses in relation to the total Kelly score did not reveal significant differences between the continent and incontinent groups (table 4 ).

There was no relationship between the presence of a psychiatric disorder and parental mental state or the marital relationship.

\section{(2) CBCL QUESTIONNAIRE DATA}

Thirty nine of the children and adolescents (27\%) had CBCL total behaviour problem T scores in the clinical range for psychopathology. This prevalence is significantly higher $(p<0.01)$ than expected based on the 82nd centile norms $(18 \%)$ or when compared with the 90th centile norm $(17 \% v 10 \%)$ used in previous research of children with chronic medical disorders using an earlier version of the CBCL. Thirty one per cent had internalising scores in the clinical range for psychopathology while the proportion with externalising scores in the clinical range was similar to the norms $(19 \%)$. There were no significant differences between the continent and incontinent groups.

The mean total problem $T$ scores of the young boys, both continent and incontinent, were significantly higher than the normative population (incontinent: 55, 95\% confidence interval (CI) 51 to $59, t 2 \cdot 57$, df $27, \mathrm{p}<0.02$; continent: $57,95 \%$ CI 51 to $63, t 2 \cdot 27$, df 15 ,

Table 4 Psychiatric disorder based on diagnostic interview in relation to total Kelly score. Values are number (\%)

\begin{tabular}{clc}
\hline $\begin{array}{l}\text { Age } \\
\text { (years) }\end{array}$ & $\begin{array}{l}\text { Continent (total } \\
\text { Kelly score 5 or 6) }\end{array}$ & $\begin{array}{l}\text { Incontinent (total } \\
\text { Kelly score } \leqslant 4)\end{array}$ \\
\hline 6-11 & $1 / 17(6)$ & $6 / 29(21)$ \\
Boys & $2 / 17(12)$ & $2 / 14(14)$ \\
Girls & $3 / 10(30)$ & $9 / 28(32)$ \\
12-17 & $2 / 11(18)$ & $4 / 19(21)$ \\
Boys & $8 / 55(15)$ & $21 / 90(23)$ \\
Tirls & & \\
\hline
\end{tabular}

No total Kelly score for 12 cases; three children not interviewed.

${ }^{\star}$ Disorder judged as present when severity rated as definite (social impairment minimal) or moderate (social impairment of a degree as to significantly interfere with everyday life). 
Table 5 CBCL $T$ scores and number of children in clinical range for behavioural problems

\begin{tabular}{|c|c|c|c|c|c|c|}
\hline \multirow[b]{2}{*}{$\begin{array}{l}\text { Age } \\
\text { (years) }\end{array}$} & \multicolumn{3}{|c|}{ Continent (total Kelly score 5 or 6) } & \multicolumn{3}{|c|}{ Incontinent (total Kelly score $\leqslant 4$ ) } \\
\hline & No & $\begin{array}{l}\text { Mean }(S D) \\
T \text { scores }\end{array}$ & $\begin{array}{l}\text { No (\%) in } \\
\text { clinical range }\end{array}$ & No & $\begin{array}{l}\text { Mean }(S D) \\
T \text { scores }\end{array}$ & $\begin{array}{l}\text { No }(\%) \text { in } \\
\text { clinical range }\end{array}$ \\
\hline \multicolumn{7}{|l|}{$6-11$} \\
\hline Boys & 16 & $56.75(11.92) \dagger$ & $7(44)$ & 28 & $55.12(10.52) \dagger$ & $9(32)$ \\
\hline Girls & 17 & $50 \cdot 71(6 \cdot 29)$ & $1(6)$ & 15 & $52.67(8.96)$ & $4(27)$ \\
\hline \multicolumn{7}{|l|}{$12-17$} \\
\hline Boys & 9 & $54 \cdot 11(10 \cdot 65)$ & $3(33)$ & 29 & $49.62(12.36)$ & $7(24)$ \\
\hline Girls & 12 & $53.00(12 \cdot 65)$ & $4(33)$ & 19 & $51 \cdot 84(11 \cdot 30)$ & $4(21)$ \\
\hline Total & 54 & & $15(28)$ & 91 & & $24(26)$ \\
\hline
\end{tabular}

Norm for mean $\mathrm{T}$ score: $50(\mathrm{SD} \bumpeq 10, \mathrm{SE} 0 \cdot 4)$.

No total Kelly scores for 12 cases; no CBCL for three cases.

*Norm for proportion in clinical range: $18 \%$ (82nd centile).

tMean $T$ scores significantly higher than norms.

$\mathrm{p}<0.05$ ) (table 5). Their mean internalising $\mathrm{T}$ scores were also significantly greater than the norms (incontinent: 57, 95\% CI 55 to 60, $t$ 3.86 , df $27, \mathrm{p}<0.001$; continent: $59,95 \% \mathrm{CI}$ 53 to $61, t 2 \cdot 87$, df $16, \mathrm{p}<0 \cdot 05)$. The mean internalising and externalising $T$ scores for the rest of the sample were close to the norms.

There was no association between the CBCL total problem scores and the total Kelly scores $(r=0 \cdot 028)$.

\section{(3) TRF QUESTIONNAIRE DATA}

Based on the teachers' ratings, $17 \%$ of the sample overall were in the clinical range for psychopathology on the total problem scale. This proportion is very similar to the normative population. These findings are consistent with the parental assessment in that the teachers tended to rate a higher proportion of the young boys and adolescents with bowel control $(20 \%)$ as showing more behavioural disorder than those who were incontinent $(15 \%)$, but differ from the parental ratings since a lower proportion of the sample overall had scores in the clinical range. In addition, the parents and teachers both rated the young incontinent girls as being less well adjusted than those with control (CBCL: incontinent $27 \%$, continent $6 \%$; TRF: incontinent $18 \%$, continent $6 \%$ ). The overall proportion of children with TRF internalising scores $(22 \%)$ and externalising scores $(14 \%)$ in the range for psychopathology, was similar to the norms.

The TRF total problem mean $T$ scores of the incontinent young girls $(52,95 \%$ CI 48 to 57) were significantly greater than those of the girls with control $(43.5,95 \%$ CI 40 to 47 , $t 2.90$, df $26, \mathrm{p}=0.007$ ) (table 6). The

Table 6 TRF T scores and number of children in clinical range for behavioural problems

\begin{tabular}{|c|c|c|c|c|c|c|}
\hline \multirow[b]{2}{*}{$\begin{array}{l}\text { Age } \\
\text { (years) }\end{array}$} & \multicolumn{3}{|c|}{ Continent (total Kelly score 5 or 6) } & \multicolumn{3}{|c|}{ Incontinent (total Kelly score $\leqslant 4$ ) } \\
\hline & No & $\begin{array}{l}\text { Mean (SD) } \\
T \text { scores }\end{array}$ & $\begin{array}{l}\text { No (\%) in } \\
\text { clinical range }\end{array}$ & No & $\begin{array}{l}\text { Mean }(S D) \\
T \text { cores }\end{array}$ & $\begin{array}{l}\text { No (\%) in } \\
\text { clinical range }\end{array}$ \\
\hline $\begin{array}{c}\text { 6-11 } \\
\text { Boys } \\
\text { Girls }\end{array}$ & $\begin{array}{l}17 \\
17\end{array}$ & $\begin{array}{l}48 \cdot 24(11 \cdot 22) \\
43.53(7 \cdot 78) \dagger\end{array}$ & $\begin{array}{l}4(24) \\
1(6)\end{array}$ & $\begin{array}{l}28 \\
11\end{array}$ & $\begin{array}{l}49 \cdot 50(9 \cdot 31) \\
52 \cdot 27(7 \cdot 80) \dagger\end{array}$ & $\begin{array}{l}4(14) \\
2(18)\end{array}$ \\
\hline $\begin{array}{c}12-17 \\
\text { Boys } \\
\text { Girls }\end{array}$ & $\begin{array}{l}8 \\
9\end{array}$ & $\begin{array}{l}56 \cdot 63(8.35) \\
50 \cdot 89(13.35)\end{array}$ & $\begin{array}{l}3(38) \\
2(22)\end{array}$ & $\begin{array}{l}28 \\
17\end{array}$ & $\begin{array}{l}49 \cdot 62(12.36) \\
50.59(9 \cdot 51)\end{array}$ & $\begin{array}{l}5(18) \\
2(12)\end{array}$ \\
\hline Total & 51 & & $10(20)$ & 84 & & $13(15)$ \\
\hline
\end{tabular}

Norm for mean $\mathrm{T}$ score: $50(\mathrm{SD} \bumpeq 10, \mathrm{SE} 0 \cdot 5 / 0 \cdot 6)$.

No total Kelly scores for 12 cases; no TRF for 14 cases.

^Norm for proportion in clinical range: $18 \%$ (82nd centile).

+ Difference between continent and incontinent groups significant at $\mathrm{p}<0.01$. difference between their internalising $\mathrm{T}$ scores was also significant (incontinent: $53,95 \% \mathrm{CI}$ 49 to 57 ; continent: $45,95 \%$ CI 42 to $48, t$ $3 \cdot 23$, df $26, p=0.003$ ). Although there were significant differences between the two groups of young girls in the study sample, the scores obtained by the young girls with good bowel control were significantly lower than the norms.

The mean internalising and externalising $\mathrm{T}$ scores for the rest of the sample, with the exception of the adolescent boys, were close to the norms.

There was a significant inverse association between the total Kelly score and the TRF total problem scores $(r=-0.202 ;$ F 5.68 $(1,133), \mathrm{p}<0.02)$.

\section{(4) DEPRESSION SELF RATING SCALE}

Any child who might have had difficulty reading or understanding the questions had each item on the questionnaire read out to them, and in most cases the younger children were questioned to see if they fully understood the more complex questions. As a precaution, the data from those who were diagnosed as being of borderline intellectual functioning were excluded from the analyses.

The DSRS revealed that for the sample overall $24 \%(35 / 148)$ of the children and adolescents rated themselves as showing depressive symptoms, with the children $(30 \%)$ rating themselves as having more symptoms than the adolescents $(17 \%)$. The difference between the age groups approached significance $\left(\chi^{2} 3 \cdot 44\right.$, df $\left.1, p=0.06\right)$.

When the samples were divided by sex and continence level (total Kelly score), this revealed a tendency for higher scores among the incontinent children and adolescents compared with those who were continent (table 7).

There was a significant association between the self report depression scale and parent rated internalising behaviour problems $(p<0.005)$. There was no association with parental mental health.

\section{MULTIVARIATE STATISTICAL ANALYSIS}

Initial univariate analyses indicated that the variables most strongly associated with outcome on the parent and/or the teacher rated assessments were the age and sex of the child and for the TRF the total Kelly score, as well as parental factors such as the marital

Table 7 DSRS in relation to levels of continence (total Kelly score). Values are number (\%)

\begin{tabular}{lll}
\hline $\begin{array}{l}\text { Age } \\
\text { (years) }\end{array}$ & $\begin{array}{l}\text { Continent (total } \\
\text { Kelly score 5 or 6) }\end{array}$ & $\begin{array}{l}\text { Incontinent (total } \\
\text { Kelly score } \leqslant 4)\end{array}$ \\
\hline 6-11 & & \\
Boys & $4 / 17(24)$ & $9 / 28(32)$ \\
Girls & $5 / 17(29)$ & $5 / 12(42)$ \\
$12-17$ & $1 / 9(11)$ & $4 / 27(15)$ \\
Boys & $1 / 11(9)$ & $5 / 17(29)$ \\
Girls & $11 / 54(20)$ & $23 / 84(27)$ \\
Total &
\end{tabular}

No total Kelly score for 10 cases. Those diagnosed as borderline intellectual functioning excluded $(n=9)$. Data for three cases missing. 
Table 8 Multiple regression analyses dependent variable CBCL total problem scores

\begin{tabular}{|c|c|c|c|c|}
\hline & Total $\mathbf{R}^{2}$ & $F(d f)$ & $\begin{array}{l}\text { Significance } \\
\text { of } F\end{array}$ & $\begin{array}{l}\text { Coefficient } B \\
(S E \text { b })\end{array}$ \\
\hline Dependent variable & $0 \cdot 169$ & $5 \cdot 57(5,137)$ & $\mathrm{p}=0.0001$ & \\
\hline $\begin{array}{l}\text { Predictor variables } \\
\text { Sex- } \\
\text { Age group (6-11, 12-17 years) } \\
\text { Kelly score } \\
\text { 'Family' score } \\
\text { Family 'education' score }\end{array}$ & & & & $\begin{array}{l}-4.95(2.91)^{\star} \\
-5.05(2.86)^{\star} \\
1.19(0.82) \\
-7.61(1.81)^{\star \star \star} \\
-3.73(1.74)^{\star \star}\end{array}$ \\
\hline
\end{tabular}

relationship, mental health scores, and educational levels. Multiple regression analyses were conducted to estimate the unique and combined contributions of these explanatory variables to child and adolescent adjustment as measured by the CBCL and TRF total problem scores. Two composite family variables were created to overcome possible interdependence among the parental variables. Firstly, a composite score of the parental mental health scores and the marital relationship scores (family); secondly, the parental educational levels (education). The 'family' score was constructed by converting each of the variables so that they were equally weighted with values ranging from 0-30 (high scores corresponding to a 'good' score), and then summing their standardised scores. Similarly, the 'education' variable was constructed by converting the parental education level variables to values ranging from $0-30$ and summing the standardised scores. To overcome the skewed distribution of the TRF scores a square root transformation was carried out.

To predict CBCL behavioural problems, a general linear model was fitted with five predictor variables. The total Kelly score, the child's gender and age group (6-11, 12-17 years) and the two composite family variables. The strongest independent predictor of outcome was the composite family variable, which explained $10 \%$ of the variance in child and adolescent adjustment (B -7.61 (SE $1.81), \mathrm{p}<0.0001)$. The education variable contributed an additional $3 \%$ of the variance (B -3.73 (SE 1.74), p<0.04). The level of continence score was not predictive (table 8 ). This model suggests that higher (good) scores on the family variable best predict a lower prevalence of behaviour problems, with girls predicted to have lower scores than the boys, and the adolescents lower scores than the children. A model testing for group differences revealed no significant interaction, indicating

Table 9 Multiple regression analyses dependent variable TRF total problem scores

\begin{tabular}{|c|c|c|c|c|}
\hline & Total $\mathbf{R}^{2}$ & $F(d f)$ & $\begin{array}{l}\text { Significance } \\
\text { of } F\end{array}$ & $\begin{array}{l}\text { Coefficient B } \\
(S E b)\end{array}$ \\
\hline $\begin{array}{l}\text { Dependent variable } \\
\text { SQRTRF } \\
\text { Predictor variables }\end{array}$ & $0 \cdot 151$ & $4 \cdot 60(5,129)$ & $p=0.0007$ & \\
\hline $\begin{array}{l}\text { Sex } \\
\text { Age group (6-11, 12-17 years) } \\
\text { Total Kelly score } \\
\text { 'Family' score } \\
\text { Family 'education' score }\end{array}$ & & & & $\begin{array}{l}-1.21(0.40)^{\star \star} \\
0.47(0.39) \\
-0.12(0.11) \\
-0.29(0.25) \\
-0.57(0.24)^{\star}\end{array}$ \\
\hline
\end{tabular}

that the family variable did not have a differential effect on the continent $v$ incontinent children and adolescents.

To predict behavioural problems as reported by teachers, the transformed TRF total problem scores were used as the dependent variable and the model was fitted with the five predictor variables listed above. The model, which is summarised in table 9 , accounted for $15 \%$ of the variance in teacher rated child and adolescent adjustment, with gender $(B-1 \cdot 21$ (SE 0.40), p <0.003) and parental educational levels ( $\mathrm{B}-0.57$ (SE 0.24), $\mathrm{p}<0.02$ ) independently contributing to the equation. This model suggests that better parental educational levels best predict a lower prevalence of behaviour problems with the girls predicted to have significantly lower scores than the boys. When these factors were accounted for, the total Kelly score was no longer an important contributor to outcome.

\section{Discussion}

The findings from this study have shown that contrary to our expectations, the incontinent children and adolescents were not less well adjusted than those with bowel control. In fact, when family factors were accounted for, no association was found between the level of faecal incontinence as measured by the total Kelly score and measures of psychological adjustment. Nevertheless, the prevalence of clinically significant emotional problems among the sample overall as assessed by the psychiatric interview, the parental assessment, and the child depression scale, was higher than expected in relation to normative populations, with a high proportion of the children showing internalising problems, as well as reporting depressive symptoms.

The only statistically significant difference between the continent and incontinent children and adolescents was among the young girls. The teachers rated the young incontinent girls as showing significantly more behaviour and internalising problems than the young girls with bowel control. Evidence suggesting some support for these findings came from two sources. Firstly, the young incontinent girls tended to have higher scores on the DSRS than the continent girls. Secondly, the parents' report of behaviour and internalising problems (CBCL) also indicated a trend towards a higher prevalence of disorder among the incontinent young girls compared with the continent young girls.

As expected, outcome based on the different methods of assessment varied. For example, the parents reported high levels of behaviour problems among the continent and incontinent young boys, but these findings did not concur with the teachers' report. There was, however, consistency in their reporting of increased internalising symptoms among the young boys (CBCL 41\%; TRF 33\%). Additionally, the psychiatric interview identified a high rate of emotional and behavioural disturbance among the adolescent boys, both continent and incontinent (continent: $30 \%$ 
and incontinent: $32 \%$, increasing to continent: $30 \%$ and incontinent: $46 \%$ when cases with 'mild' problems were included). On the other hand, based on the teachers' report, the adolescents who had achieved continence tended to be more disturbed than the incontinent adolescent boys (continent $38 \%$; incontinent $18 \%$ ). Differences between the assessment measures, which have also been reported in many recent studies, ${ }^{26} 27$ reflect not only the differing perspectives of the respondents, but the checklists measure somewhat different aspects of psychosocial functioning than the interview methods. Moreover, although the checklists have sound psychometric properties, compared with semistructured interviews, they have the disadvantage of not being suitable for probing symptoms, and may also be more sensitive to parental educational levels. An additional factor, which is common to studies of children with chronic medical problems, is, that with the possible exception of the teachers, all concerned were aware of the nature of the child's disability and whether the child was continent or incontinent.

Contrary to our predictions those who were still incontinent by the time they reached adolescence were not, as a group, more emotionally disturbed than those with bowel control. We hypothesised that for children with chronic faecal incontinence, adolescence would be a particularly stressful time, since the social problems associated with their disability as well as those associated with the physical and emotional changes of puberty and emerging sexuality, would be intensified. Moreover, limited control over a sensitive area of physical functioning together with the need to adjust emotionally to the adult implications of their disability, were likely to interfere with emotional development. In addition, Ditesheim and Templeton's study showed that the 'quality of life' of incontinent children over the age of 10 was less good than for younger children. ${ }^{8}$ Although the data from the psychiatric interview indicated a relatively high rate of psychological distress among the incontinent adolescents $(40 \%$ including cases rated as mild), this was not significantly different from that among the continent adolescents (24\%). Moreover, based on parent and teacher behaviour ratings and the self report questionnaire, there was no evidence of an increased prevalence of behavioural and emotional disturbance among this sample of incontinent adolescents when compared with those who were continent. This suggests that the majority of the incontinent adolescents in this study had come to terms with their disability. Over time, the chronic nature of their problem appeared to have stimulated psychologically protective factors such as positive coping strategies. Moreover the parents of these children may have come to accept from early on that, due to the 'severity' of the condition, their child would never be able to achieve normal bowel control. Consequently parental sensitivity to the problems the child may have had to cope with could act as a protective factor if parental functioning itself was not adversely affected.
The variables with the strongest explanatory power for the differences on the CBCL total problem scores were parental mental health and the marital relationship, but these variables were not important explanatory variables for outcome as measured by the psychiatric interview, the TRF, or the DSRS. It is possible that parents with higher levels of psychological distress and/or lower levels of marital satisfaction are more likely to report behaviour problems, or these children may indeed be more behaviourally maladjusted, which in itself affects marital satisfaction and parental health. It is also possible that better functioning families are more sensitive to their child's condition, symptoms, and distress.

The explanatory variable common to outcome as measured by both the CBCL and TRF was the level of parental education, especially the fathers. The better the parents' education the lower the children's behaviour problem scores. With this exception, the findings indicated no major effect of family background factors such as social class, birth position, and number of siblings.

Another unexpected finding was that, based on a number of the assessment measures, a higher proportion of the study sample had scores indicating psychopathology when compared with normative populations. These findings, which are comparable with other studies of children with chronic medical disorders, suggest that parents of children who are born with anorectal anomalies overcompensate for their child's early life threatening problems. As we found in a longitudinal study of children who underwent major neonatal surgery, ${ }^{28}$ mothers tended to be ineffective and inconsistent in their responses to their children's behaviour and this is known to be detrimental to future emotional and behavioural adjustment. $^{29}$

In conclusion, in the care of children with chronic physical problems, one aim is to try to minimise the relationship between physical and emotional difficulties. Because faecal incontinence is socially unacceptable, and clinical experience has indicated a link between physical and emotional difficulties, the principal aim of this study was to assess whether there was a relationship between persistent faecal incontinence and emotional adjustment. The findings have shown that at the time of interview, the incontinent children and adolescents, with the possible exception of the young girls, were not more emotionally disturbed than those with bowel control.

The findings from this study cannot, however, account for the important concerns about cause and effect, because the data were cross sectional. Assessing whether faecal incontinence produces effects on the child's psychological adjustment or whether the child's emotional adjustment affects their ability to achieve socially acceptable levels of bowel control can only be addressed in a longitudinal study. In addition, it is known that certain characteristics of a child, and of his or her parents or family, may have positive or negative effects on a child's psychological 
adjustment. Among this sample of young people higher parental educational levels were associated with lower levels of behavioural difficulties, whereas poor parental mental health and low marital satisfaction were strongly related to higher levels of behavioural disturbance. None of these parental factors, however, were related to levels of faecal incontinence. Although we hypothesised that chronic faecal incontinence would have a negative effect on family life, and the interview data certainly highlighted the very considerable problems the parents and children had to contend with, the cross sectional nature of the data do not allow us to elucidate whether faecal incontinence produces an alteration in parental mental health and marital satisfaction, or whether these parental factors affect the child's desire to achieve social control of his or her bowels, or whether both are simultaneously or reciprocally related.

Despite these reservations, this study, which is the first to examine in detail the relationship between faecal incontinence and emotional adjustment in a large group of children treated for anorectal anomalies, offers encouragement to the children and their families, but it also indicates that these children are at risk for difficulties with psychosocial adjustment. Outcome and compliance with treatment may be enhanced if, from an early age, psychological evaluation of the child and experienced advice and guidance for the families, regardless of the level of faecal incontinence, becomes an integral part of their continuing care.

This research was funded by the Leverhulme Trust. We would like to thank Mr Drake FRCS, Mr Brereton FRCS, and the senior registrars for their contribution. We would also like to thank all the children and their parents who took part in the study.

1 Breslau N. Psychiatric disorder in children with physical disabilities. Fournal of the American Academy of Child Psychiatry 1985; 24: 87-94.

2 Cadman D, Boyle M, Szatmari P, Offord DR. Chronic illness, disability, and mental and social well-being: findings of the Ontario Child Health Study. Pediatric 1987; 79: 805-13.

3 Steinhausen HC. Chronically ill and handicapped children and adolescents: personality studies in relation to disease. f Abnorm Child Psychol 1981; 9: 291-7.

F Abnorm Child Psychol 1981; 9: 291-7.
4 Pless BI. Clinical assessment: physical and psychological functioning. Pediatr Clin North Am 1984; 31: 33-45.

5 Rutter M, Tizard J, Whitmore $\mathrm{K}$. Education, health and behaviour. London: Longmans, 1970.

6 Drotar D, Doershuk CF, Stern RC, Boat TF, Boyer W, Matthews L. Psychosocial functioning of children with cystic fibrosis. Pediatrics 1981; 67: 338-43.
7 Wallander JL, Varni JW, Babani L, Barnis HT, Wilcox KT. Children with chronic physical disorders: maternal reports of their psychological adjustment. $¥$ Pediatr Psychol 1988; 13: 197-212.

8 Ditesheim JA, Templeton JM Jr. Short-term v long-term quality of life in children following repair of high imperforate anus. 7 Pediatr Surg 1987; 22: 581-7.

9 Ginn-Pease ME, King DR, Tarnowski KJ, Green L, Young G, Linscheid TR. Psychosocial adjustment and physical growth in children with imperforate anus or abdominal wall defects. F Pediatr Surg 1991; 26: 1129-35.

0 Stephens FD, Durham Smith E. Classification, identification, and assessment of surgical treatment of anorectal anomalies. Pediatric Surgery International 1986; 1: $200-5$.

11 Kelly JH. The clinical and radiological assessment of anal continence in childhood. Aust NZ 7 Surg 1972; 42 62-3.

12 Graham P, Rutter $M$. The reliability and validity of the psychiatric assessment of the child. 1 . Interview with the psychiatric assessment of the child. 1. Inter

13 Richman N, Stevenson JE, Graham PJ. Preschool to school: a behavioural study. London: Academic Press, 1982

14 Goldberg DF. Manual of the general health questionnaire. Windsor: National Foundation for Educational Research Publishing Company, 1978.

15 Spanier GB. Measuring dyadic adjustment: new scales for assessing the quality of marriage and similar dyads. fournal of Marriage and the Family 1976; 38: 15-28.

16 Hodges K, Kline J, Fitch P, McKnew D, Cytryn L. Child assessment schedule: a diagnostic interview for research and assessment schedule: a diagnostic interview for research and
clinical use. Catalog of Selected Documents in Psychology, clinical use. Catal

17 Rutter M, Graham P. The reliability and validity of the psychiatric assessment of the child. 1. Interview with the child. Br $\mathcal{F}$ Psychiatry 1968; 114: 563-79.

18 Hodges K. Assessing children with a clinical research interview: the child assessment schedule. In: Prinz RJ, ed. Advances in behavioural assessment of children and families. Grenwich, CT: JAI Press, 1987: 203-33.

19 Verhulst FC, Berden GFM, Sanders-Woudstra JAR Mental health in Dutch children. II. The prevalence of psychiatric disorder and relationships between measures. Acta Psychiatr Scand 1985; 72 (suppl 324): 1-44.

20 Verhulst FC, Althaus M, Berden GFMG. The child Verhulst FC, Althaus M, Berden GFMG. The child
assessment schedule: parent-child agreement and validity measures. F Child Psychol Psychiatry 1987; 28: 455-66

21 Achenbach TM. Manual for the child behaviour checklist/4-18 and 1991 profile. Burlington, VT: University of Vermont, Department of Psychiatry, 1991.

22 Birleson $P$. The validity of depressive disorder in childhood and the development of a self-rating scale: a research note. f Child Psychol Psychiatry 1981; 22: 73-88.

23 Fundudis T, Berney TP, Kolvin I, et al. Reliability and validity of two self-rating scales in the assessment of childhood depression. Br $\mathcal{F}$ Psychiatry 1991; 159 (suppl 11): $36-40$.

24 Achenbach TM. Manual for the teacher's report form and 1991 profile. Burlington, VT: University of Vermont, Department of Psychiatry, 1991.

25 Pearce J. Child health surveillance for psychiatric disorder: practical guidelines. Arch Dis Child 1993; 69: 394-8.

26 Achenbach TM, McCopnaughy SH, Howell CT. Child/adolescent behavioural and emotional problems: implications of cross-informant correlations for situational specificity. Psychol Bull 1987; 101: 213-32.

27 Eiser C. Psychological effects of chronic disease. 7 Child Prychol Pychiogical

28 Ludman L, Lansdown R, Spitz L. Effects of early hospitalization and surgery on the emotional development of 3 year olds: an exploratory study. European Child and Adolescent Psychiatry 1992; 1: 186-95.

29 Quinton D, Rutter M. Parental breakdown: the making and breaking of intergenerational links. Aldershot: Gower, 1988 . 